\title{
EVALUASI PENGENALAN TATA CARA BERWUDHU DALAM PENGEMBANGAN PENDIDIKAN AGAMA ISLAM MELALUI MEDIA GAMBAR PADA KELOMPOK B DI RA ASIAH KOTA PEKANBARU
}

\author{
AFIYAH, MELWANY MAY PRATAMA, \\ RIZKY NURHASANAH, IDA WINDI WAHYUNI \\ Pendidikan Islam Anak Usia Dini \\ Fakultas Agama Islam Universitas Islam Riau \\ afiyah052@gmail.com \\ melwany06@gmail.com \\ rizkynurhasanaah@gmail.com \\ idawindi@fis.uir.ac.id
}

\begin{abstract}
This study aims to introduce the procedure for ablution in the development of Islamic education through the medium of the slowdown in group B in RA Asiah, Pekanbaru city. The research was carried out because there were problems in the introduction of ablution procedures. The results of the observation on the evaluation of the introduction of ablution procedures in the development of Islamic education through the propagating media in group B in RA Asiah can be concluded that the introduction of the procedure for ablution through the image media is carried out optimally. The activity of introducing the procedures for the ablution of children given by educators goes according to the expectations and achievements of development, which are used as indicators of implementation on aspects of strength and balance.
\end{abstract}

Key Words: Introduction, Procedures, Ablution, Media, Images

\section{PENDAHULUAN}

Pendidikan anak usia dini merupakan upaya pembinaan yang ditujukan kepada anak sejak lahir sampai dengan usia enam tahun yang dilakukan melalui pemberian stimulus pendidikan agar membantu perkembangan, pertumbuhan baik jasmani maupun rohani sehingga anak memiliki kesiapan memasuki pendidikan yang lebih lanjut (Yamin, dan Sanan, 2013). Pendidikan anak usia dini merupakan pendidikan yang paling mendasar dan menempati kedudukan sebagai golden age dan sangat strategis dalam pengembangan sumber daya manusia (Direktorat PAUD, 2005). Usia lahir sampai 
GENERASI EMAS

Jurnal Pendidikan Islam Anak Usia Dini

Volume 2, No. 1, 2019

dengan memasuki pendidikan dasar merupakan masa keemasan sekaligus masa kritis dalam tahapan kehidupan manusia, yang akan menentukan perkembangan anak selanjutnya. Masa ini merupakan masa yang tepat untuk meletakkan dasar-dasar pengembangan kemampuan fisik, bahasa, sosial-emosional, konsep diri, seni moral, dan nilai-nilai agama (Yamin, dan Sanan, 2013). Penerapan nilai-nilai agama hendaknya dilakukan sedini mungkin sebagai bekal masa depan dan akhirat (Wahyuni, I. W, 2018).

Beberapa pendapat yang
mendefinisikan pengertian dari
Pendidikan Agama Islam. Menurut Abdul Majid, Pendidikan Agama Islam adalah usaha sadar yang dilakukan dalam rangka mempersiapkan siswa untuk meyakini, memahami, dan mengamalkan ajaran Islam melalui bimbingan, pengajaran yang ditentukan untuk mencapai tujuan yang telah ditetapkan. Sedangkan Zakiyah Darajat mengartikan Pendidikan Agama Islam sebagai perubahan sikap dan tingkah laku sesuai dengan petunjuk Agama Islam.
http://digilib.uinsby.ac.id/8924/4/Bab.

\section{\%20II.pdf}

Kegiatan pendidikan anak usia dini mesti dijadikan upaya pembinaan karakter anak dengan berbasis nilainilai agama yang akan menjadi pagar dalam menghadapi krisis pergeseran nilai-nilai moral. Berdasarkan Permendiknas No. 58 Tahun 2009 tentang Standar Pendidikan Anak Usia Dini, bahwa tingkat pencapaian perkembangan menggambarkan pertumbuhan dan perkembangan yang diharapkan dicapai anak pada rentang usia tertentu. Perkembangan anak yang dicapai merupakan integrasi aspek pemahaman nilai-nilai agama dan moral, fisik, bahasa, kognitif dan sosial emosional (Direktorat PAUD Direktur Jendral Pendidikan Nonformal dan Informal Kemendiknas 2010). Ada tiga strategi pengembangan nilai-nilai agama pada anak usia dini, yaitu: (1) Strategi kegiatan rutinitas; (2) Strategi kegiatan terintegrasi; (3) Strategi kegiatan khusus (Satibi, 2004, dalam Arif, 2016).

Perkembangan berasal dari kata dasar "kembang" mendapat awalan "pe" dan akhiran "an". Artinya perbuatan yang menjadikan tambah 
GENERASI EMAS

Jurnal Pendidikan Islam Anak Usia Dini

Volume 2, No. 1, 2019

sempurna (tentang pribadi, pikiran, dan pengetahuan). Dalam proses pengembangan objek juga ikut berperan (Choiriyah, 2019).

Kata keagamaan berasal dari kata dasar agama dan mendapat awalan ke dan akhiran -an; yang artinya adalah kepercayaan kepada Tuhan; hal-hal gaib yang memiliki kekuatan besar; aqidah; din (ul) (Choiriyah, 2019).

Dalam buku Psikologi Agama karya Jalaluddin Rahmat, menurut Harun Nasution, Agama mengandung arti ikatan yang harus dipegang dan di patuhi manusia. Ikatan dimaksud berasal dari suatu kekuatan yang lebih dari manusia sebagai kekuatan yang gaib yang tak dapat ditangkap dengan panca indra, namun mempunyai pengaruh yang besar sekali terhadap kehidupan manusia sehari-hari. Keagamaan merupakan segala sesuatu yang berhubungan dengan agama. Artinya, segala hal baik berupa sikap, ritual maupun kepercayaan yang bersifat agama masuk kedalam keagamaan (Choiriyah, 2019).

Karakteristik keagamaan pada usia anak adalah:

a. Munculnya jiwa keagamaan anak.

Ada beberapa teori timbulnya keagamaan anak, yakni: rasa ketergantungan. Manusia dilahirkan ke dunia ini memiliki empat kebutuhan, yakni keinginan untuk perlindungan (security), keinginan akan pengalamn baru (new experience), keinginan untuk dapat tanggapan (response), dan keinginan untuk dikenal (recognition). Berdasarkan kenyataan dan kerjasama dari keempat keinginan itu, maka bayi sejak dilahirkan hidup dalam ketergantungan. Melalui pengalaman-pengalaman yang diterimanya dari lingkungan itu kemudian terbentuklah rasa keagamaan pada diri anak.

b. Instink keagamaan. Bayi yang dilahirkan sudah memiliki beberapa instink. Diantaranya instink keagamaan. Belum terlihatnya tindak keagamaan pada diri anak karena beberapa fungsi kejiwaan yang menopang kematangan berfungsinya instink itu belum sempurna. Dengan demikian, pendidikan agama perlu diperkenalkan kepada anak jauh sebelum usia 7 tahun. Artinya, jauh sebelum usia tersebut, nilai-nilai keagamaan perlu ditanamkan 
GENERASI EMAS

Jurnal Pendidikan Islam Anak Usia Dini

Volume 2, No. 1, 2019

kepada anak sejak usia dini. Nilai keagamaan itu sendiri bisa berarti perbuatan yang berhubungan antara manusia dengan Tuhan atau hubungan antar sesama manusia. (Choiriyah, 2019).

Permasalahan yang dialami anak kelompok B di RA Asiah adalah anak hanya belajar melalui bercakap-cakap, belum ada dilaksanakan pembelajaran kegiatan pengalaman cara berwudhu melalui media gambar sehingga hanya sebagian anak bisa dalam menyebutkan urutan cara berwudhu yang benar, hanya sebagian anak bisa dalam melafalkan niat sebelum berwudhu, serta sebagian anak bisa menempel urutan gambar cara berwudhu yang benar sesuai urutannya dengan menggunakan media gambar. Selama ini anak hanya bisa melihat gambar di dinding-dinding kelas, poster-poster cara berwudhu tetapi anak tidak mengerti apa maksud dan tujuan dari gambar-gambar tersebut.

\section{Peningkatan kemampuan} berwudhu pada anak usia dini, yakni anak memiliki kemampuan berwudhu. Maksudnya anak meningkatkan potensi berupa kesanggupan atau kekuatan untuk berusaha dengan dirinya sendiri mulai dari melafalkan niat berwudhu, membersihkan anggota badan tertentu dan cara tertentu dengan menggunakan air, serta dimulai dengan niat untuk menghilangkan hadast kecil sebagai syarat sahnya sholat, dan melafalkan doa setelah berwudhu (Nuraini. 2015).

Berdasarkan uraian di atas, maka penulis tertarik mengadakan penelitian tentang evaluasi perkembangan moral dan agama untuk meningkatkan pengetahuan berwudhu anak dengan media gambar pada Kelompok B di RA Asiah.

Wudhu menurut bahasa, dibaca dengan fathah huruf waw (wadhu), artinya nama sebuah tempat yang digunakan untuk berwudhu, yang kata asalnya al-wadha'ah, artinya bersih. Sedangkan, wudhu menurut istilah adalah beberapa bentuk pekerjaan khusus yang diawali dengan niat (Lailatul, 2016).

Wudhu merupakan gerbang atau kunci pertama dalam melaksanakan ibadah mahdah, karena wudhu menjadi salah satu syarat sah dari ibadah tersebut seperti sembahyang fardhu atau sembahyang sunah, ketika hendak melakukan thawaf $\mathrm{Ka}$ 'bah. Maka dari itu sebagai guru kita harus memperlihatkan, melakukan dan 
GENERASI EMAS

Jurnal Pendidikan Islam Anak Usia Dini

Volume 2, No. 1, 2019

menyampaikan informasi dengan jelas dan baik (showing, doing, and telling) kepada anak kita dalam meningkatkan kemampuan berwudhu supaya apa yang mereka lihat dan perintah yang mereka dengar dapat diterima otak anak dengan baik. https://media.neliti.com/media/publica tions/215580-none.pdf

Wudhu adalah mensucikan diri dari segala hadast kecil sesuai dengan syariat agama islam dengan menggunakan air. Dengan berpedoman kepada Al-Qur'an dan Al-Hadist, perintah berwudhu sesuai dengan firman Allah SWT, dalam AlQur'an Surat Al-Maidah ayat 6, yaitu
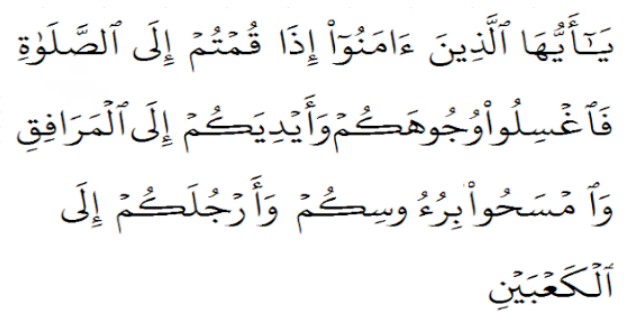

Pengertian wudhu dalam bahasa yaitu "bersih dan indah". Sedangkan, menurut syarat dan syariat Islam wudhu adalah mengunakan air pada anggota tubuh badan tertentu dengan cara tertentu yang dimulai dengan niat guna menghilangkan hadist kecil (Seadie, 1996: 19,12).

Syarat wudhu menurut Seadie (1996: 11), adalah keutamaan- keutamaan atau perbuatan-perbuatan yang dipenuhi sebelum melakukan suatu pekerjaan, tanpa memenuhi ketentuan atau perbuatan tersebut, suatu pekerjaan tidah sah. Rukun wudhu terdiri dari niat, membasuh muka, membasuh kedua tangan sampai siku, mengusap sebagian kepala atau rambut kepala, membasuh kedua kaki telapak kaki sampai mata kaki, tertib (sesuai dengan urutan), dan doa setelah wudhu (Nuraini. 2015).

Rukun wudhu, yaitu (1) niat, (2) membasuh muka, (3) membasuh kedua tangan sampai siku, (4) mengusap sebagian kepala atau rambut, (5) membasuh kedua kaki sampai mata kaki, (6) tertib dan berurutan (Buku PAI, 2014 dalam Akmal, 2018). Adapun sunnah wudhu adalah (1) membaca basmalah, (2) membasuh kedua telapak tangan, (3) berkumur-kumur, (4) membersihkan kedua lubang hidung, (5) mengusap kedua telinga, (6) semua yang dibasuh diulang tiga kali, (7) mendahulukan anggota badan yang kanan, dan (8) berdoa sesudah wudhu (Buku PAI, 2014 dalam Akmal, 2018).

\section{Mempelajari perkembangan} manusia dan makhluk-makhluk lain pada umumnya, harus membedakan 
GENERASI EMAS

Jurnal Pendidikan Islam Anak Usia Dini

Volume 2, No. 1, 2019

dua hal, yaitu proses pematangan (pematangan berarti proses pertumbuhan yang menyangkut penyempurnaan fungsi-fungsi tubuh sehingga mengakibatkan perubahanperubahan dalam tingkah laku terlepas dari ada atau tidak adanya proses belajar) dan proses belajar (belajar, berarti mengubah atau memperbaiki tingkah laku melalui latihan, pengalaman dan kontak dengan lingkungan pada manusia penting sekali belajar melalui kontak sosial agar manusia hidup dalam masyarakat dengan struktur kebudayaan yang rumit itu). Selain itu masih ada ketiga yang ikut menentukan kepribadian yaitu kepribadian atau bakat (Sarwono,1976:26). Dijelaskan dalam Q.S. Al-Mu'min ayat 67 menjadi bukti perkembangan anak pada umumnya.
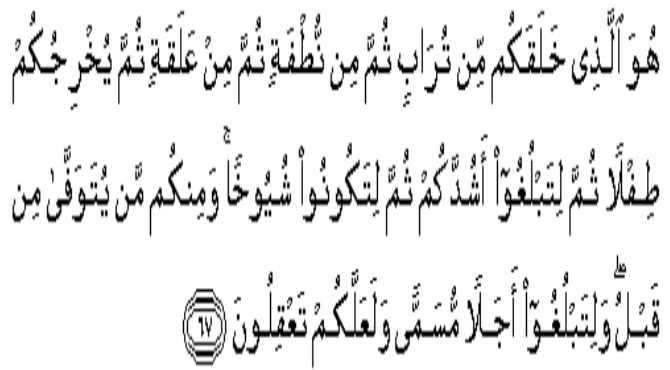

Artinya: Dia-lah yang menciptakan kamu dari tanah kemudian dari setetes mani, sesudah itu dari segumpal darah, kemudian dilahirkannya kamu sebagai seorang anak, kemudian (kamu dibiarkan hidup) supaya kamu sampai kepada mas (dewasa), kemudian (dibiarkan kamu hidup lagi) sampai tua, diantara kamu ada yang diwafatkan sebelum itu. (kami perbuat demikian) supaya kamu sampai kepada ajal yang ditentukan dan supaya kamu memahami(nya) (Departemen Agama RI, 2010: 346).

Begitu juga dengan jiwa keagamaan pada anak juga ikut berkembang, pada waktu dilahirkan anak memang belum beragama. Anak baru memiliki potensi atau fitrah untuk menjadi manusia beragama. Bayi juga belum mempunyai kesadaran beragama, tetapi telah memiliki potensi kejiwaan dan dasardasar ber-Tuhan. Isi, warna, dan corak keagamaan anak sangat 25 dipengaruhi oleh keimanan, sikap dan tingkah laku keagamaan orang tuanya (Ahyadi, 2005: 40).

Menurut Raharjo (2012: 27- 28), perkembangan keagamaan pada anak adalah proses yang dilewati oleh seseorang untuk mengenal Tuhannya. Sejak manusia dilahirkan dalam keadaan lemah fisik maupun psikis, walaupun dalam keadaan yang demikian anak telah memiliki 
GENERASI EMAS

Jurnal Pendidikan Islam Anak Usia Dini

Volume 2, No. 1, 2019

kemampuan bawaan yang bersifat laten, yakni fitrah keberagamaan. Potensi ini memerlukan pengembangan melalui bimbingan dari orang yang lebih dewasa dan pemeliharaan yang mantap yang lebih pada usia dini. http://eprints.walisongo.ac.id/7074/3/

\section{BAB\%20II.pdf}

Menyuruh anak sebagai anggota keluarga untuk berwudhu merupakan kewajiban bagi orang tua terutama ayah. Perintah Allah kepada orang tua untuk melaksanakan wudhu tidaklah mudah, sederhana, sekedar memerintahkan dan membutuhkan waktu yang pendek, didalamya tersirat banyak perintah lainya yang berkaitan dengan proses pendidikan anak yang tidak sepi dari rintangan dan tantangan, serta membutuhkan waktu yang panjang. Melalui ayat tersebut menjelaskan bahwa orang tua terhadap anak-anaknya dalam rangka melatih keterampilan mereka berwudhu. Berdasarkan observasi sementara, sejak kecilpun ada kalanya saat-saat di mana anak tersebut malas melaksanakan wudhu, hal ini akan selalu dijumpai hampir setiap anak, bahkan yang orang tuanya disiplin dalam hal setiap hendak melaksanakan sholat berwudhu lebih dahulu, apalagi yang tidak dididik berwudhu sejak kecil. Begitu juga dengan anak-anak di RA Asiah Simpang Tiga yang beralamat di Jalan Tengku Bay, pembinaan ibadah wudhu masih bersifat terbatas, guru hanya seminggu sekali mengajak anak-anak untuk praktek wudhu serta anak-anak di kelas jarang diajarkan do'a wudhu serta gerakan-gerakan tertibnya berwudhu, sehingga masih banyak anak belum mengetahui bagaimana praktek berwudhu yang benar. Lingkungan berperan penting dalam perkembangan kehidupan seorang anak (Khurrotul, 2015).

Kata media di dalam kamus umum Bahasa Indonesia diartikan sebagai suatu alat atau sarana untuk menyebarluaskan informasi seperti radio, surat kabar, TV, dan sebagainya. Kemudian dalam Bahasa Arab yang dikutip dari bukunya Azhar Arsyat, kata media diartikan sebagai perantara wasailun, atau sebuah pengantar pesan kepada penerima. Sedangkan kata media secara garis besar adalah manusia, materi, atau kejadian, yang dapat membangun kondisi dan membuat siswa mampu memperoleh pengetahuan, 
GENERASI EMAS

Jurnal Pendidikan Islam Anak Usia Dini

Volume 2, No. 1, 2019

keterampilan, atau sikap (Rozak, 2011).

Media juga merupakan suatu perantara atau tempat intik menyalurkan pesan dan informasi belajar. Fungsi media gambar menurut B.E.F Montolalu (2008: 9,10) adalah sebagai berikut: fungsi edukatif. Mendidik dan memberikan pengaruh positif yang baik pada pendidikan anak fungsi sosial, memberikan informasi yang autentik dan pengalaman berbagai bidang kehidupan memberikan konsep yang sama kepada setiap orang. Fungsi ekonomis, meningkatkan produksi belajar (belajar anak) melalui pembinaan. Fungsi seni budaya dan telekomunikasi yang mendorong dan menimbulkan ciptaan baru termaksud pola usaha penciptaan teknologi kemedian yang modern (Nuraini. 2015).

\section{METODOLOGI PENELITIAN}

Penelitian ini, penulis menggunakan metode penelitian evaluai kualitatif untuk mendeskripsikan dan menganalisa fenomena-fenomena yang terjadi di RA Asiah dalam pengenalan tata cara berwudhu untuk pengembangan pendidikan Agama Islam melalui media gambar. Jumlah siswa di kelas B RA Asiah, yaitu 14 orang. Dalam penelitian ini sumber data diperoleh dari informan, peristiwa, dan dokumen. Adapun informan yaitu, siswa, guru dan juga kepala sekolah RA Asiah. Peristiwa yang diamati, yaitu kegiatan pengenalan tata cara berwudhu dalam pengembangan pendidikan Agama Islam melalui media gambar Dan dokumentasi selama kegiatan berlangsung.

Penelitian kualitatif dalam (Sugiyono, 2007), merupakan penelitian dilakukan dengan natural setting, sumber data primer, dan teknik pengumpulan data lebih banyak pada observasi partisipan, wawancara, dan dokumentasi. Sesuai dengan hal tersebut, dalam penelitian ini cara pengambilan data dengan menggunakan teknik sebagai yaitu, observasi partisipan, wawancara dan dokumentasi.

\section{HASIL DAN PEMBAHASAN}

RA Asiah sebelumnya bernama TK Islam Asiah Terpadu yang bergabung dengan Lembaga Pembinaan dan Pengembangan Taman kanak-kanak Al-Qur'an Badan Komunikasi Pemuda Remaja Masjid 
GENERASI EMAS

Jurnal Pendidikan Islam Anak Usia Dini

Volume 2, No. 1, 2019

Indonesia (LPPTKA BKPRMI) pada tanggal 28 November 2007 sampai Tahun 2015. Kemudian berubah menjadi Raudhatul Athfal (RA) Asiah Tahun 2015 dan bergabung dengan Kementrian Agama Kota PekanBaru hingga saat ini. Dengan Nomor Statistik $101214710072 \quad$ yang diselenggarakan oleh Yayasan Asiah. RA Asiah beralamat di Jalan Tengku Bey Ujung Komplek Peputra Jaya Blok II No. 85, Kelurahan Simpang Tiga Kecamatan Bukitraya Kota Pekanbaru.

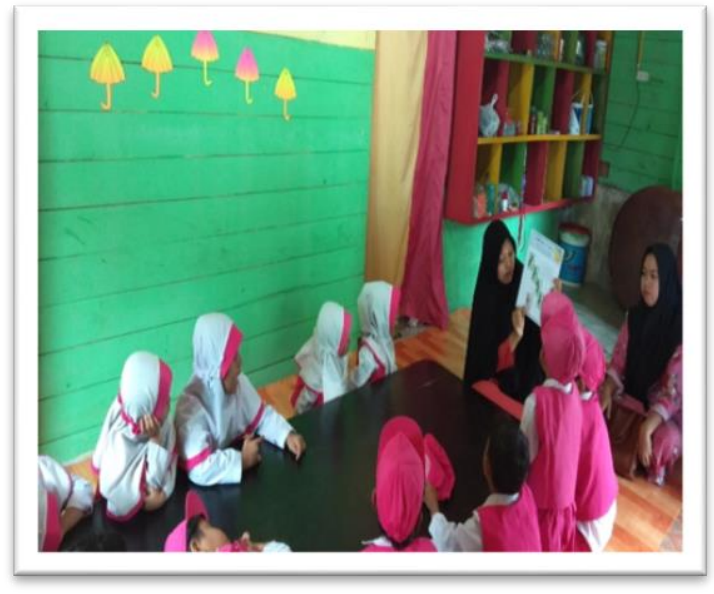

Gambar 1. Pengenalan Tata Cara Berwudhu

Berdasarkan penelitian yang dilakukan, diperoleh hasil bahwa anak RA Asiah sudah mampu mengenal tata cara berwudhu melalui media gambar. Terlihat anak dapat menyusun tata cara berwudhu. Dalam penelitian tema yang diajarkan adalah agama. Saat guru menerangkan tata cara berwudhu anak tampak antusias. Setelah anak menerima informasi dari guru, dan diajak anak menyusun dan mampu antri dan memberi informasi tentang pengenalan tata cara berwudhu.

Berdasarkan hasil observasi dan wawancara oleh peneliti dapat disimpulkan bahwa kegiatan melalui media gambar sudah dilakukan oleh guru saat proses pembelajaran dalam kelas dan luar kelas. Dan dari hasil observasi ini diperkuat dengan hasil wawancara yang dilakukan peneliti dengan salah satu pendidik di RA Asiah, setiap anak memiliki kemampuan yang berbeda sehingga tingkat keberhasilan anak juga berbeda.

Hasil observasi dan wawancara yang telah peneliti dapatkan, disimpulkan bahwa pendidikan tidak harus menekankan pada hasil kemampuan peserta didik, melainkan pendidik harus terus membimbing dan memberikan motivasi agar pengenalan tata cara berwudhu anak dapat berkembang secara optimal dan sesuai dengan kemampuan anak.

Mengingat masa kanak-kanak adalah petualang dan pembelajaran 
GENERASI EMAS

Jurnal Pendidikan Islam Anak Usia Dini

Volume 2, No. 1, 2019

sejati yang penuh kejujuran dalam merealisasikannya pikiran dan mengekspresikan perasaannya. Semua orang tua tentu ingin membahagiakan anak-anaknya, melihat mereka tumbuh sehat, cerdas, dan sukses dalam kehidupannya serta aktif dalam bergerak agar anak sehat baik secara jasmani maupun rohani.

\section{PENUTUP}

Hasil penelitian yang telah dilaksanakan pengenalan tata cara bewudhu melalui media gambar di RA Asiah berjalan dengan baik. Karena anak-anak terlihat mampu mengerjakan tugas yang diberikan. Hasil pengamatan terhadap evaluasi pengenalan tata cara berwudhu anak melalui media gambar di RA Asiah dapat disimpulkan bahwa pengenalan tata cara berwudhu melalui media gambar dilaksanakan secara optimal. Kegiatan pengenalan tata cara berwudhu anak yang diberikan oleh pendidik berjalan sesuai harapan dan pencapaian perkembangan, yang dijadikan sebagai indikator pelaksanaan pada aspek kekuatan dan keseimbangan.

\section{DAFTAR PUSTAKA}

Akmal, Aulia. 2018. Penerapan Metode Demonstrasi dalam Meningkatkan Kemampuan Berwudhu pada Kelompok B3 TK Islam YLPI Marpoyan. Generasi Emas, Vol. 1 No. 1.

Arif, Hakim. 2016. Pengembangan Nilai-Nilai Agama dan Moral di Taman Kanak-Kanak. Jurnal Pendidikan Islam Ta'dib, Vol. V, No.1. Tahun 2016. file:///C:/Users/asus/AppData/Lo cal/Temp/1980-5571-1-PB.pdf. Diakses pada 04 Maret 2019.

Anggraini, Wardah dan Syafrimen. Pengembangan Nilai-Nilai Moral dan Agama pada Anak Usia Dini. Universitas Islam Negeri Raden Intan Lampung. file:///C:/Users/asus/AppData/Lo cal/Temp/1.\%20Wardah\%20An ggraini\%20Konsep\%20Paper2.pdf. Diakses pada 25 Maret 2019.

Azizah, Ferihah. 2015. Metode Pembelajaran Nilai Agama dan Moral Pada Anak Usia Dini Di Bustanul Athfal 'Aisyiyah. Skripsi.

http://repository.iainpurwokerto. ac.id/901/1/COVER $\% 2 C \% 20 \mathrm{~B}$ AB\%20I\%2C\%20V\%2C\%20D AFTAR\%20PUSTAKA.pdf. Diakses pada 04 Maret 2019.

Choiriyah, Amin. 2019. Pengembangan Keagamaan Pada Anak Usia Dini (Studi Kasus Di TK 'Aisyiyah Bustanul Athfal Karang Malang Yogyakarta). Skripsi. http://digilib.uinsuka.ac.id/3782/1/BAB\%20I\%2 
GENERASI EMAS

Jurnal Pendidikan Islam Anak Usia Dini

Volume 2, No. 1, 2019

C\%20IV\%2C\%20DAFTAR\%20

PUSTAKA.pdf. Diakses pada 08

Mei 2019.

Fatchiyyah, Lailatul. 2016.

Peningkatan Hasil Belajar

Materi Rukun Wudhu Dengan

Media Kartu Gambar Siswa

Kelas 1 Madrasah Ibtidaiyah

Darussalam Ngepreh Sayung

Demak Tahun Pelajaran

2015/2016. Skripsi.

Nuraini. 2015. Peningkatan Pengetahuan

Berwhudu Dengan Menggunakan

Media Gambar Pada Anak Usia 5-6

Tahun. Artikel penelitian.

https://jurnal.sttgarut.ac.id/index.ph

p/algoritma/article/viewFile/168/38

1. Diakses pada 25 Maret 2019.

Wahyuni, Ida Windi. 2018. Penerapan

Nilai-Nilai Moral pada Santri TPQ Al-Khumaier

Pekanbaru. Generasi Emas:

Jurnal Pendidikan Islam Anak

Usia Dini, Vol. 1 No. 1.

Yamin, Martinis. dan Sanan, Jamilah

Sabri. 2013. Panduan PAUD

Pendidikan Anak Usia Dini.

Jakarta: Referensi (Gaung

Persada Press Group).

http://eprints.walisongo.ac.id/7074/3/

BAB\%20II.pdf. Diakses pada 16

Mei 2019.

https://media.neliti.com/media/publica

tions/215580-none.pdf Diakses

pada 20 Mei 2019. 